\title{
Human Platelets Produce Granulocyte-Macrophage Colony-Stimulating Factor and Delay Eosinophil Apoptosis
}

\author{
Silvina Raiden, Jorge Schettini, Gabriela Salamone, Analía Trevani, \\ Mónica Vermeulen, Romina Gamberale, Mirta Giordano, and Jorge Geffner \\ Laboratory of Immunology (SR, JS, GS, AT, MV, RG, MG, JG), Institute of Hematologic Research, National \\ Academy of Medicine, and Laboratory of Immunogenetics (RG, MG, JG), Department of Microbiology, Buenos \\ Aires University School of Medicine, Buenos Aires, Argentina
}

SUMMARY: An association between eosinophils and platelets has been described in several diseases, most notably asthma. Although the mechanisms through which platelets influence eosinophil behavior are not well defined, platelets seem to contribute to the selective accumulation of eosinophils at sites of allergic inflammation by virtue of their ability to produce eosinophil chemotactic factors. We report here for the first time that platelets delay apoptosis, thus enhancing eosinophil survival. A marked inhibition of spontaneous apoptosis was observed using eosinophil:platelet ratios of 1:50, 1:25, 1:10, and 1:5. Moreover, promotion of eosinophil apoptosis by either pronase or dexamethasone was also inhibited greatly in the presence of platelets. The antiapoptotic effect mediated by platelets was dependent on the release of soluble products and was significantly inhibited by neutralizing antibodies directed to GM-CSF. Studies performed by flow cytometry, directed to analyze the cellular source of this cytokine, demonstrated that intracytoplasmic GM-CSF is present in resting platelets. Moreover, GM-CSF was found in platelet supernatants, at concentrations able to prevent eosinophil apoptosis. Our findings support a novel mechanism through which platelets may contribute to eosinophil accumulation at allergic inflammatory sites. (Lab Invest 2003, 83:589-598).

$E$ osinophils play a critical role in the pathogenesis of asthma and allergic diseases. During the course of allergic inflammation, eosinophils are selectively recruited in the skin or mucosa, and upon activation, they release potent inflammatory mediators, including toxic cationic proteins, oxygen metabolites, proteolytic enzymes, and several cytokines, which contribute to the initiation and maintenance of the allergic inflammatory response (Costa et al, 1997; Dombrowicz and Capron, 2001; Gleich, 2000). Resolution of this response is dependent, at least in part, on the rate of eosinophil apoptosis, which seems to be a crucial factor in determining the steady-state number of eosinophils at the site of inflammation (Simon and Blazer, 1995; Walsh, 2000). The uptake of apoptotic eosinophils is mediated by both professional and nonprofessional phagocytes, such as smooth muscle cells, lung fibroblasts, and airway epithelial cells (Haslett, 1999; Platt et al, 1998; Walsh, 2000; Walsh et al, 1999). It is interesting that this process not only prevents spillage of the eosinophil's histotoxic con-

\section{DOI: 10.1097/01.LAB.0000062851.71286.47}

Received October 10, 2002.

This study was supported by grants from the Consejo Nacional de Investigaciones Cientificas y Técnicas (CONICET), Buenos Aires University School of Medicine, and Agencia Nacional de Promoción Cientifica y Tecnológica (FONCyT), Argentina.

Address reprint requests to: Dr. Jorge R. Geffner, Laboratorio de Inmunología, IIHEMA, Academia Nacional de Medicina, Pacheco de Melo 3081, 1425 Buenos Aires, Argentina. E-mail: geffnerj@fibertel.com.ar tents but also induces the release of anti-inflammatory cytokines by macrophages, such as IL-10, transforming growth factor $\beta$ (TGF- $\beta$ ), and prostaglandin E2 (Haslett, 1999; Perssen and Erjefalt, 1997; Platt et al, 1998; Stern et al, 1996; Walsh, 2000; Walsh et al, 1999).

Signals from the microenvironment can delay or accelerate apoptosis of eosinophils. Cytokines such as IL-3, IL-5, IL-13, and GM-CSF enhance eosinophil survival, thus promoting the accumulation and persistence of eosinophils at sites of inflammation (Lopez et al, 1986; Luttman et al, 1996; Rothenberg et al, 1988; Yamaguchi et al, 1991). By contrast, IL-4, TGF- $\beta$, IL-12, and glucocorticoids, as well as ligation of the type II integral membrane signaling receptor CD69 or the tyrosine phosphatase-linked panleukocyte receptor CD45, accelerate the spontaneous rate of eosinophil apoptosis (Alam et al, 1994; Blaylock et al, 1999; Nutku et al, 2001; Wallen et al, 1991; Walsh et al, 1996; Weidi et al, 1998).

Several lines of evidence suggest that the behavior of eosinophils in allergic diseases is influenced by platelets. From guinea pig models, it was suggested that platelets are a prerequisite component in allergic asthma, because platelet depletion reduced eosinophil infiltration into the lung after allergen exposure to sensitized animals (Lellouch-Tubiana et al, 1988). Consistent with these results are observations made in allergic rabbits that indicated that animals rendered thrombocytopenic showed a marked reduction in the number of eosinophils in the bronchoalveolar lavage fluid, as well as in the magnitude of the late asthmatic 
response and airway hyperresponsiveness (Coyle et al, 1990). Moreover, studies performed in allergic subjects suggested not only that platelet-dependent events determine exacerbation of asthma but also that platelets recovered from the bronchoalveolar lavage fluid of patients with asthma are often associated with eosinophils and also show evidence of degranulation (Gleich, 1990; Knauer et al, 1981; Morley et al, 1985; Page, 1988; Page and Coyle, 1989; Yasuba et al, 1991). The mechanisms through which platelets influence eosinophil behavior are not well defined. However, there are known mediators released by platelets, such as RANTES, ATP, PAF, and platelet factor 4, which induce chemotaxis of eosinophils (Burgers et al, 1993; Chihara and Nakajima, 1989; Kameyoshi et al, 1992; Wardlaw et al, 1986). They may contribute to the selective accumulation of eosinophils at sites of allergic inflammation.

No previous reports have examined the ability of platelets to modulate the rate of eosinophil apoptosis. We report here for the first time that platelets release GM-CSF enhancing eosinophil survival. Our findings support the notion that platelets may play a role not only in promoting selective eosinophil infiltration after antigen challenge but also in perpetuating the allergic inflammatory response by virtue of their ability to improve eosinophil survival.

\section{Results}

\section{Platelets Delay Spontaneous Apoptosis, Enhancing Eosinophil Survival}

For analyzing whether platelets were able to modulate eosinophil apoptosis, cells were cultured at $37^{\circ} \mathrm{C}$ for 48 hours with unstimulated platelets, at eosinophil:platelet ratios of 1:25, 1:10, and 1:5, and apoptosis was revealed by fluorescence microscopy. Figure 1 shows that platelets markedly decreased eosinophil apoptosis. We next examined whether delayed apoptosis resulted in the enhancement of eosinophil survival. To this aim, eosinophils $\left(1 \times 10^{6} / \mathrm{ml}\right)$ were cultured for 96 hours at $37^{\circ} \mathrm{C}$ in the absence

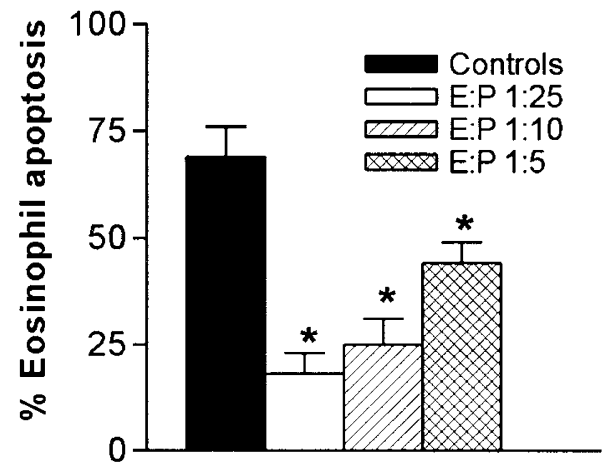

Figure 1.

Platelets delay spontaneous apoptosis of eosinophils. Eosinophils $(1 \times$ $10^{6} / \mathrm{ml}$ ) were cultured at $37^{\circ} \mathrm{C}$ for 48 hours in the absence (controls) or presence of washed platelets (eosinophil:platelet ratios 1:25, 1:10, and 1:5). Then, the percentages of apoptotic cells were determined by fluorescent microscopy. Results are expressed as the mean \pm SEM of eight experiments; ${ }^{*} p<0.01$, platelets versus controls. (controls) or presence of unstimulated platelets (eosinophil:platelet ratio $1: 50)$, and the percentages of eosinophil viability were determined by fluorescence microscopy as described in "Materials and Methods." It was found that platelets dramatically increased eosinophil survival (survival of eosinophils $=9 \pm 6$ versus $62 \pm 12 \%$, control versus platelet-treated; $n=$ $11, p<0.001)$.

All of these experiments were carried out using washed platelets. To rule out the possibility that washing procedures used for platelet purification might influence the ability of platelets to prevent eosinophil apoptosis, we performed another set of experiments using platelets purified by gel filtration. It was found that gel-filtered platelets (GFP), used at an eosinophil:platelet ratio of $1: 50$, prevented apoptosis in a comparable way as washed platelets did (apoptosis of eosinophils at 48 hours $=74 \pm 9$ versus $23 \pm 5 \%$, control versus GFP-treated; $n=5, p<0.001$ ).

During the course of apoptosis, phosphatidylserine (PS), a negatively charged phospholipid, becomes exposed at the cell surface (Homburg et al, 1995). Eosinophil apoptosis was then analyzed by flow cytometry using FITC-labeled annexin-V, which specifically binds to PS, in combination with propidium iodide staining. Figure 2A shows that the presence of platelets resulted in a marked reduction in the percentage of annexin-V-positive cells. Apoptosis was also examined by propidium iodide staining and flow cytometry. In agreement with the observations described above, we found that the proportion of eosinophils that display a hypodiploid DNA peak (ie, apoptotic cells) was markedly lower for eosinophils cultured in the presence of platelets than in control cells (Fig. 2B).

Although the above experiments were performed using unstimulated platelets, the isolation and culture of platelets was shown to be associated with the induction of a significant degree of activation as measured by the expression of P-selectin, a granule protein that becomes localized at platelet surface after activation (McEver, 1994). In fact, we found that after 30 minutes of incubation at $37^{\circ} \mathrm{C}$ in culture medium supplemented with $1 \%$ human serum albumin (HSA; Sigma, St. Louis, Missouri), $87 \pm 16 \%$ of platelets showed moderate levels of P-selectin expression (mean fluorescence intensity $=36 \pm 14, n=4$ ) which, as expected, were significantly lower $(p<0.01)$ than those showed by platelet stimulated during 5 minutes at $37^{\circ} \mathrm{C}$ without stirring by thrombin $(1 \mathrm{U} / \mathrm{ml})$ or collagen $(0.20 \mathrm{mg} / \mathrm{ml}$; mean fluorescence intensity = $169 \pm 23$ and $96 \pm 17$, respectively, $n=3$ ). We then performed additional experiments to determine whether platelet-activating agents, such as thrombin and collagen, might improve the ability of platelets to delay eosinophil apoptosis. In preliminary studies, we observed that thrombin increased the rate of eosinophil apoptosis by acting directly on eosinophils themselves (not shown). Therefore, we carried out subsequent experiments using collagen, which did not induce any direct effect on eosinophils. Cultures were performed at different eosinophil:platelet ratios, in the 
A
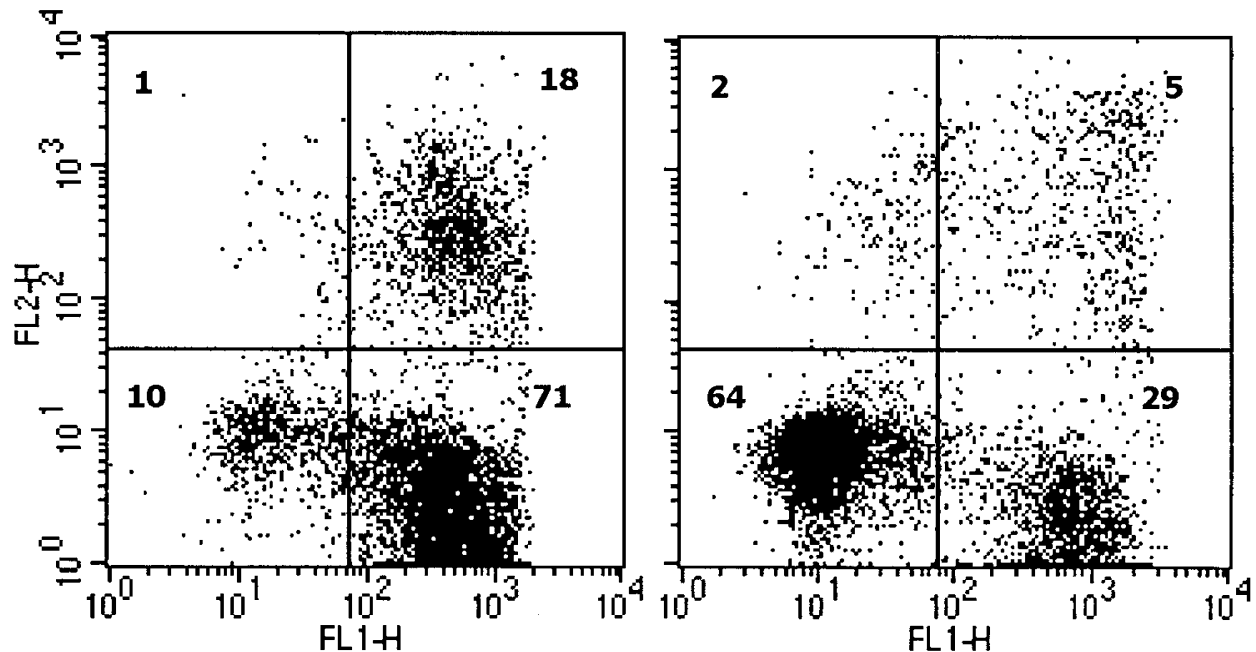

B

$\mathrm{FL} 1 \mathrm{H}$

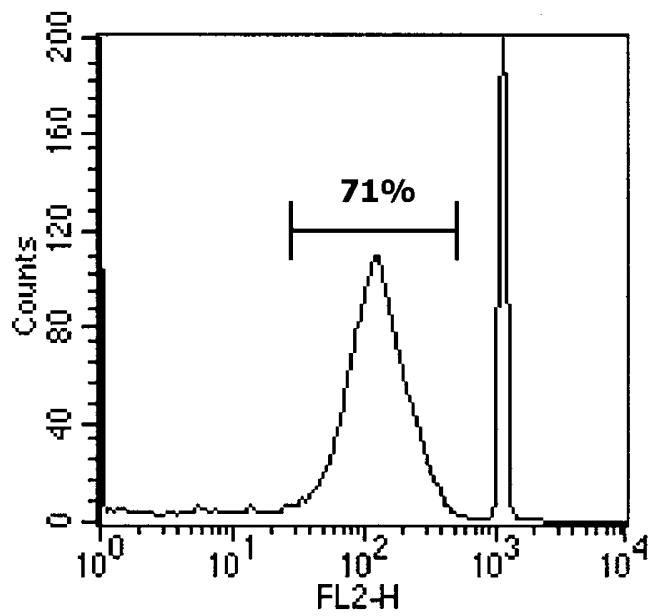

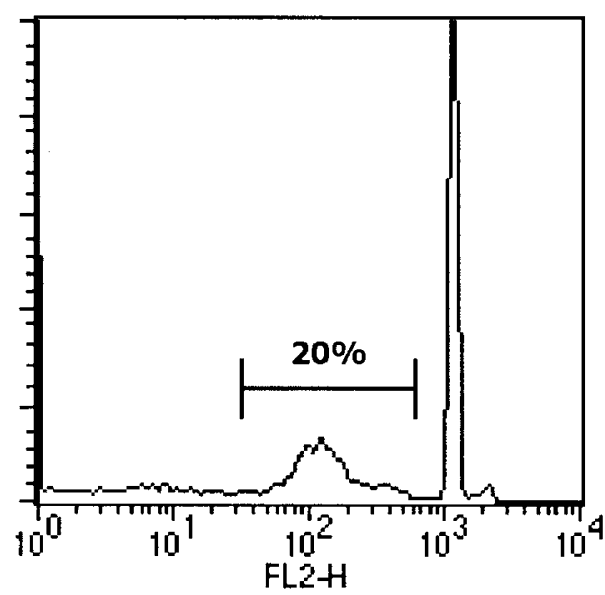

Figure 2.

Inhibition of eosinophil apoptosis mediated by platelets measured by annexin- $V$ binding assay or evaluation of propidium iodide fluorescence of individual nuclei. Eosinophils $\left(1 \times 10^{6} / \mathrm{ml}\right)$ were cultured for 48 hours at $37^{\circ} \mathrm{C}$ in the absence (left) or presence (right) of platelets (eosinophil:platelet ratio 1:50). A, Cells were labeled with annexin-V FITC (FL1-H) and propidium iodide (FL2-H) for 20 minutes at $4^{\circ} \mathrm{C}$, and the percentages of apoptotic cells were analyzed by two-color flow cytometry. $\mathrm{B}$, Apoptosis was analyzed by propidium iodide staining of individual nuclei, as described in "Material and Methods." A representative experiment is shown ( $n=3$ ).

absence or presence of collagen $(0.20 \mathrm{mg} / \mathrm{ml})$, and apoptosis was revealed at 48 hours by fluorescence microscopy. Results in Figure 3 showed that collagen did not improve the ability of platelets to delay eosinophil apoptosis.

\section{Platelets Inhibit Promotion of Eosinophil Apoptosis Induced by Pronase and Dexamethasone}

Having shown that platelets delayed the spontaneous rate of eosinophil apoptosis, we then analyzed whether platelets were also able to inhibit the action of apoptosis-promoting agents. We have previously reported that exposure to proteolytic enzymes such as pronase markedly enhances human neutrophil apoptosis (Trevani et al, 1996). Because preliminary experiments showed that this phenomenon was also observed in human eosinophils, we then investigated whether platelets prevented stimulation of eosinophil apoptosis triggered by pronase. We also investigated whether platelets were able to prevent stimulation of eosinophil apoptosis by dexamethasone (Wallen et al, 1991). These experiments are described in Figure 4. We found that platelets efficiently inhibited promotion of apoptosis induced by either pronase or dexamethasone.

\section{Inhibition of Eosinophil Apoptosis Is Dependent on the Release of Antiapoptotic Factor(s) by Platelets}

In an attempt to determine whether the ability of platelets to increase eosinophil survival was dependent on the release of soluble factors, we carried out incubations using semipermeable cell culture inserts. As described in "Materials and Methods," eosinophils were placed into the upper compartment, while culture medium (controls) or platelets (eosinophil:platelet ratio $=1: 50$ ) were added to the lower compartment. Both compartments were separated by a TransWell insert, which allows the passage of macromolecules 


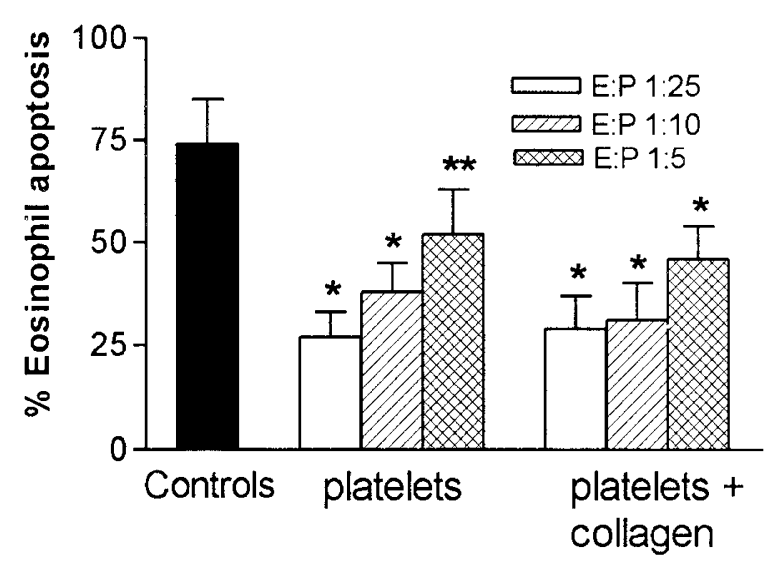

Figure 3.

Collagen does not improve the ability of platelets to delay eosinophil apoptosis. Eosinophils $\left(1 \times 10^{6} / \mathrm{ml}\right)$ were cultured at $37^{\circ} \mathrm{C}$ for 48 hours with or without collagen $(0.20 \mathrm{mg} / \mathrm{ml})$, at different eosinophil:platelet ratios. Then, the percentages of apoptotic cells were determined by fluorescent microscopy. Results are expressed as the mean \pm SEM of five experiments. Eosinophils cultured with collagen in the absence of platelets show similar levels of apoptosis than control cells: $70 \pm 9(n=5) ;{ }^{*} p<0.01,{ }^{* *} p<0.05$, platelets versus controls.

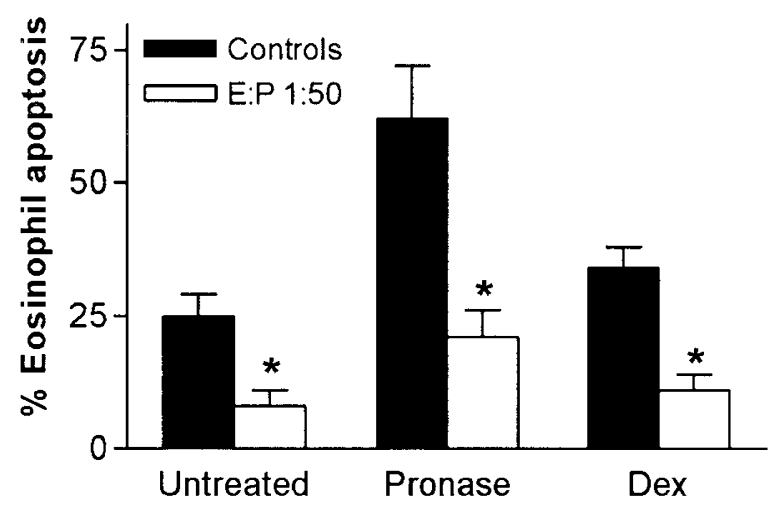

Figure 4.

Platelets prevent promotion of eosinophil apoptosis induced by pronase and dexamethasone. Untreated or pronase-treated eosinophils (cell treated with $100 \mu \mathrm{g} / \mathrm{ml}$ of pronase for 30 minutes at $37^{\circ} \mathrm{C}$ in saline, washed four times and resuspended in pronase-free medium supplemented with $1 \% \mathrm{HSA}$ ), at a concentration of $1 \times 10^{6} / \mathrm{ml}$, were cultured at $37^{\circ} \mathrm{C}$ for 24 hours in the absence $(\square)$ or presence of platelets (eosinophil:platelet ratio $1: 50 ; \square$ ). Dexamethasone $(1 \mu \mathrm{M})$ was added at the beginning of the cell culture. Percentages of apoptotic cells were determined by fluorescent microscopy. In the absence of platelets both, pronase and dexamethasone significantly ( $p<$ 0.05 ) increased the percentages of eosinophil apoptosis. Results are expressed as the mean \pm SEM of six experiments; ${ }^{*} p<0.01$, platelets versus controls.

but prevents cell to cell contact. Apoptosis was evaluated after 48 hours of culture by fluorescence microscopy. The results showed that, under these conditions, platelets were able to prevent eosinophil apoptosis in a comparable manner to that observed in mixed suspensions of eosinophils and platelets (see Fig. 1): $\%$ apoptosis $=78 \pm 11$ versus $26 \pm 8$, untreated versus platelet-treated eosinophils, respectively (mean \pm SEM, $n=4, p<0.01$ ). This result indicates that direct contact between eosinophils and platelets is not required to prevent apoptosis. Supporting this observation, we also found that superna- tants from unstimulated platelets were able to delay eosinophil apoptosis. In fact, when eosinophils $(1 \times$ $10^{6} / \mathrm{ml}$ ) were incubated at $37^{\circ} \mathrm{C}$ for 48 hours with supernatants $(20 \% \mathrm{vol} / \mathrm{vol})$ harvested from platelet suspensions $\left(5 \times 10^{8} / \mathrm{ml}\right.$ cultured alone for 18 hours at $37^{\circ} \mathrm{C}$ in medium supplemented with $1 \% \mathrm{HSA}$ ), a marked inhibition of eosinophil apoptosis was observed: $\%$ apoptosis $=74 \pm 8$ versus $27 \pm 11$, untreated versus platelet supernatant-treated eosinophils, respectively (mean \pm SEM, $n=7, p<0.001$ ). It is interesting that results from Figure 5 indicate that these supernatants were also able to induce the activation of freshly isolated eosinophils, as shown by the induction of $\mathrm{Ca}^{2+}$ transient responses, suggesting that the inhibition of eosinophil apoptosis is associated with cellular activation.

\section{Role of GM-CSF in the Delayed Eosinophil Apoptosis Mediated by Platelets}

Upon activation, platelets release a wide range of inflammatory mediators, including different cytokines such as platelet-derived growth factor, TGF- $\beta 1$, and IL-1 (Deuel et al, 1982; Grainger et al, 1995; Hawrylowicz et al, 1989). Moreover, several members of the chemokine family, including platelet factor 4 (PF4), $\beta$-thromboglobulin ( $\beta$-TG), ENA78, RANTES, and IL-8, are produced by platelets (Burgers et al, 1993; Chihara and Nakajima, 1989; Kameyoshi et al, 1992; Shao-Bo et al, 1996). The most important survival cytokines for eosinophils are IL-3, IL-5, and GM-CSF (Lopez et al, 1986; Rothenberg et al, 1988; Yamaguchi et al, 1991). Although no previous reports have examined whether platelets are able to produce these cytokines, it has

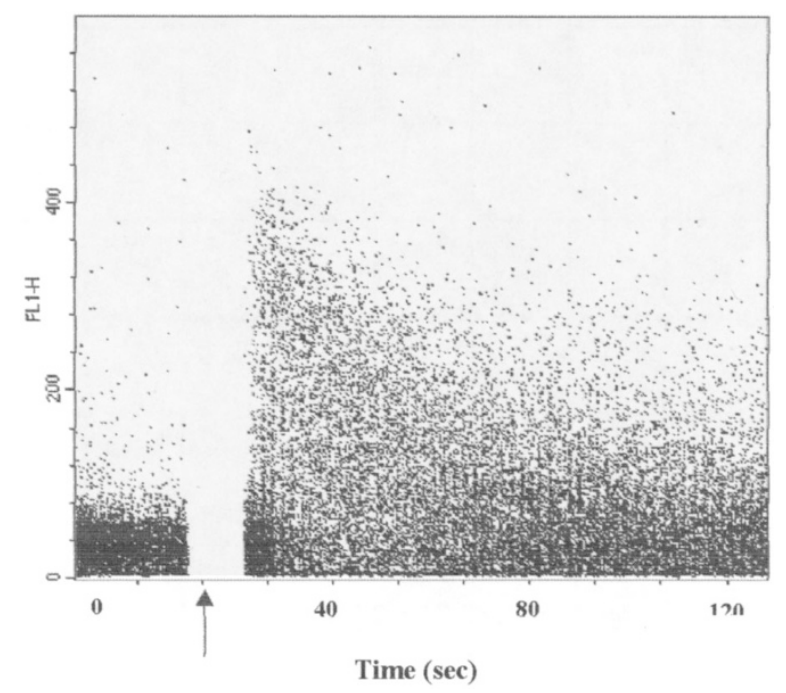

Figure 5.

Platelet supernatants trigger rises of intracellular $\mathrm{Ca}^{2+}$ concentrations in eosinophils. Platelets $\left(5 \times 10^{8} / \mathrm{ml}\right.$ in medium supplemented with $\left.1 \% \mathrm{HSA}\right)$ were cultured for 18 hours at $37^{\circ} \mathrm{C}$, and platelet supernatants were then harvested. Eosinophils were loaded with fluo- 3/AM as described in "Materials and Methods." The basal levels of fluo-3 fluorescence were recorded for approximately 15 seconds. Then, platelet supernatant $(20 \% \mathrm{vol} / \mathrm{vol})$ was added and fluorescence was recorded for 100 seconds. The increase in $\left[\mathrm{Ca}^{2+}\right]_{i}$ was recognized as an increase in fluo-3 fluorescence. Results from a representative experiment $(n=5)$ are depicted. 
been shown that megakaryocytes release both IL-3 and GM-CSF (Jian et al, 1994; Nimer and Uchida, 1995; Nimer et al, 1996; Wickenhauser et al, 1995). Thus, we speculated that inhibition of eosinophil apoptosis might involve the release of IL-3 and/or GMCSF by platelets, and to test this hypothesis, we first analyzed whether blocking antibodies directed to IL-3 or GM-CSF were able to prevent the antiapoptotic effect mediated by platelets. Preliminary experiments were performed to determine the concentrations of anti-GM-CSF and anti-IL-3 antibodies needed to prevent inhibition of eosinophil apoptosis mediated by 5 to $20 \mathrm{ng} / \mathrm{ml} \mathrm{GM-CSF}$ and IL-3, respectively. At concentrations of $2 \mu \mathrm{g} / \mathrm{ml}$, both antibodies almost completely block the ability of these cytokines to delay eosinophil apoptosis (not shown). Taking this into account, supernatants harvested from unstimulated platelets cultured for 18 hours at $37^{\circ} \mathrm{C}$ were treated with 2 and $10 \mu \mathrm{g} / \mathrm{ml}$ neutralizing antibodies directed to GM-CSF or IL-3, and after 10 minutes at $37^{\circ} \mathrm{C}$, these supernatants were added to eosinophils, and apoptosis was revealed after 48 hours of culture by fluorescence microscopy. The results showed that anti-GMCSF but not anti-IL-3 antibodies significantly prevented inhibition of eosinophil apoptosis by platelet supernatants (Fig. 6), supporting a role for GM-CSF in this phenomenon. It should be noted, however, that blocking antibodies directed to GM-CSF, even used at concentrations higher than that shown in Figure 6, did not abolish the antiapoptotic effect of supernatants (data not shown), suggesting that other mechanisms not related to the presence of GM-CSF might also be involved.

Because no previous studies have analyzed the ability of platelets to release GM-CSF, we performed another set of experiments to test whether platelets may be the cellular source of GM-CSF. Flow cytometric assays revealed the presence of intracellular GMCSF in resting platelets (Fig. 7). Moreover, quantifica-

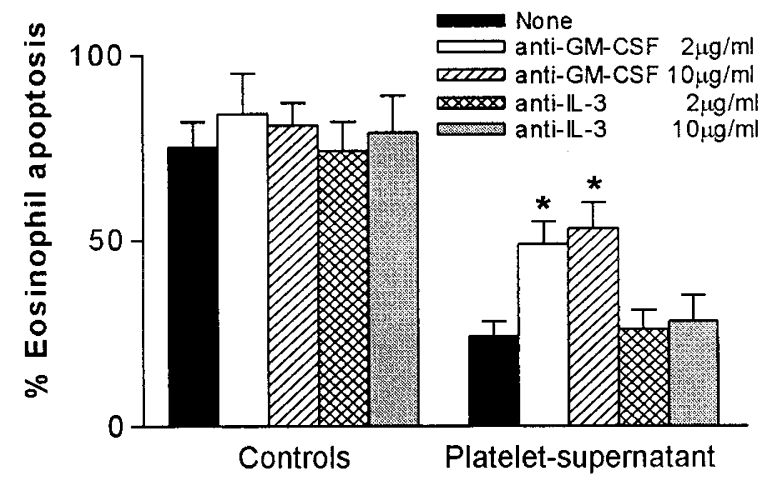

Figure 6.

Neutralizing antibodies to GM-CSF partially inhibit the delay of eosinophil apoptosis mediated by platelet supernatants. Neutralizing antibodies directed to GM-CSF or IL-3 were added to supernatants, obtained from platelets $(5 \times$ $10^{8} / \mathrm{ml}$ ) cultured for 18 hours at $37^{\circ} \mathrm{C}$. After 10 minutes at $37^{\circ} \mathrm{C}$, these supernatants were added to eosinophils $\left(1 \times 10^{6} / \mathrm{ml}, 20 \% \mathrm{vol} / \mathrm{vol}\right)$, and apoptosis was revealed by fluorescent microscopy after 48 hours of culture at $37^{\circ} \mathrm{C}$. Results are expressed as the mean \pm SEM of four experiments; ${ }^{*} p<$ 0.01 versus eosinophils cultured with platelet supernatant in the absence of anti-GM-CSF antibodies.

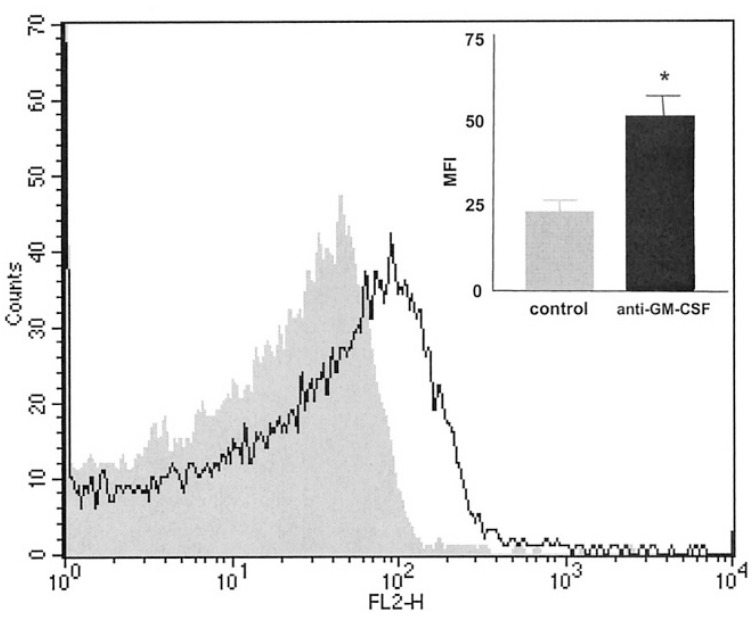

Figure 7.

Flow cytometric analysis of intracellular GM-CSF in platelets. Washed platelets $\left(1 \times 10^{7}\right)$ were fixed and permeabilized and subsequently stained with 0.25 mg of PE-rat anti-human GM-CSF mAb (PE-BVD2-21C11 Ab). To demonstrate specificity of staining, the binding of the PE-rat anti-human GM-CSF was blocked by preincubation of the fixed/permeabilized platelets with $2.5 \mathrm{mg}$ of unlabeled rat anti-human GM-CSF mAb (unlabeled-BVD2-21C11 Ab) before staining (control, gray area). A representative experiment is shown. Inside the Figure, the mean values of mean fluorescence intensity \pm SEM of four experiments are shown; ${ }^{*} p<0.05$ versus control.

tion of GM-CSF in the supernatants of platelets $(5 \times$ $10^{8} / \mathrm{ml}$ ) collected either after 18 hours of culture at $37^{\circ} \mathrm{C}$ in RPMI medium supplemented with $1 \% \mathrm{HSA}$ or after platelet disruption by repeated freezing and thawing revealed the presence of GM-CSF (29 \pm 7 and $43 \pm 10 \mathrm{pg} / \mathrm{ml}$, respectively, mean $\pm \mathrm{SEM}, n=7$ ) at concentrations able to inhibit eosinophil apoptosis (Okada et al, 1998; Tai et al, 1991). Moreover, we also observed that supernatants from platelets disrupted by freezing markedly prevented eosinophil apoptosis and that this effect could be partially attributable to the presence of GM-CSF, because neutralizing antibodies directed to GM-CSF significantly inhibited this antiapoptotic effect: \% apoptosis after 48 hours of culture at $37^{\circ} \mathrm{C}: 78 \pm 17,23 \pm 12$, and $52 \pm 13$, for eosinophils cultured in medium alone and in medium supplemented with $20 \% \mathrm{vol} / \mathrm{vol}$ of platelet supernatants, in the absence or presence of $10 \mu \mathrm{g} / \mathrm{ml}$ neutralizing antibodies directed to GM-CSF, respectively (mean \pm SEM, $n=4, p<0.05$, eosinophils cultured with platelet supernatants in the absence and presence of anti-GM-CSF antibodies).

Finally, we analyzed the relationship between platelet activation and GM-CSF secretion. Washed platelets $\left(5 \times 10^{8} / \mathrm{ml}\right.$ in RPMI medium supplemented with $1 \% \mathrm{HSA}$ ) were incubated at $37^{\circ} \mathrm{C}$ for 15 minutes in the absence or presence of collagen $(0.20 \mathrm{mg} / \mathrm{ml})$. Supernatants were collected, and the levels of GMCSF were evaluated by ELISA. We observed that activation by collagen resulted in a marked increase in the secretion of GM-CSF: $10 \pm 7$ versus $38 \pm 12$ $\mathrm{pg} / \mathrm{ml}$, for platelets incubated in the absence or presence of collagen, respectively (mean $\pm \mathrm{SEM}, n=5, p<$ 0.01). 


\section{Discussion}

Eosinophils are the hallmark of allergic inflammation. They are selectively recruited at allergic inflammatory sites and contribute to the initiation and maintenance of the allergic response by virtue of their ability to release a considerable array of inflammatory mediators (Costa et al, 1997; Dombrowicz and Capron, 2001; Gleich, 2000). Eosinophil numbers in inflammatory sites can be related to a balance between incoming recruited cells and apoptotic death followed by phagocytic clearance, two different but interrelated processes that determine the tissue load of eosinophils (Walsh, 2000).

We report here for the first time that platelets delay eosinophil apoptosis, increasing cell survival. Not only spontaneous apoptosis but also promotion of apoptosis induced by agents such as pronase and dexamethasone were markedly inhibited by platelets. Inhibition of apoptosis was dependent on the release of soluble factors by platelets, and it was partially prevented by neutralizing antibodies directed to GM-CSF.

Aside from their well-established role in hemostasis, platelets seem to play an important role in several inflammatory processes. A large body of evidence supports not only that platelets are present at allergic inflammatory sites but also that platelet-dependent events determine exacerbation of allergic responses (Burgers et al, 1993; Chihara and Nakajima, 1989; Coyle et al, 1990; Gleich, 1990; Kameyoshi et al, 1992; Knauer et al, 1981; Lellouch-Tubiana et al, 1988; Morley et al, 1985; Page, 1988; Page and Coyle, 1989; Wardlaw et al, 1986; Yasuba et al, 1991). The mechanisms involved have not been well defined; however, attention has been focused on the ability of platelets to promote eosinophil accumulation by releasing a number of eosinophil chemotactic factors (Burgers et al, 1993; Chihara and Nakajima, 1989; Kameyoshi et al, 1992; Wardlaw et al, 1986). Our results support the notion that platelets may contribute to perpetuate the allergic inflammatory response not only by inducing the selective recruitment of eosinophils at allergic inflammatory sites but also by increasing eosinophil survival.

We also show here for the first time that platelets are a source of GM-CSF. Studies performed by flow cytometry demonstrated that intracellular GM-CSF is present in resting platelets. Moreover, GM-CSF was found in platelet supernatants, at concentrations able to prevent eosinophil apoptosis. Our results support the notion that GM-CSF released by platelets accounts, at least in part, for the inhibition of eosinophil apoptosis mediated by platelets. Eosinophils are also able to produce GM-CSF; however, in agreement with previous work showing that in resting eosinophils GM-CSF mRNA is rapidly degraded, preventing mRNA accumulation and GM-CSF protein production (Esnault and Malter, 2001; Moqbel et al, 1991), we did not detect any production of GM-CSF in eosinophils cultured alone. This observation does not rule out the possibility that eosinophil activation induced by platelets may trigger the production of GM-CSF. In fact, it has been shown that the prevention of eosinophil apoptosis by mast cells is dependent on the induction of GM-CSF production by eosinophils themselves (Levi-Schaffer et al, 1998). However, this mechanism does not seem to be involved in our experimental model, because kinetic studies showed that neutralizing antibodies directed to GM-CSF strongly suppressed the ability of platelet supernatants to delay eosinophil apoptosis when added at the beginning of the cell culture. By contrast, these antibodies exert a weak suppressor effect when added 30 minutes after the exposure of eosinophils to platelet supernatants (S. Raiden, unpublished results). Because the induction of GM-CSF production by stimulated eosinophils requires at least 2 hours of culture (Moqbel et al, 1991), this result suggests that GM-CSF released by platelets is responsible for the increase of eosinophil survival.

We have previously reported that platelets are also able to delay neutrophil apoptosis (Andonegui et al, 1997). In contrast with the observations made in eosinophils, we found that inhibition of neutrophil apoptosis was dependent on direct cell to cell interactions between platelets and neutrophils. In fact, we observed similar levels of apoptosis using viable or fixed platelets, whereas platelet supernatants did not mediate any significant effect. Because GM-CSF prolongs survival of both neutrophils and eosinophils (Haslett, 1999; Lopez et al, 1986), it is not clear why platelet supernatants, which contain GM-CSF, were unable to prevent neutrophil apoptosis. One possible explanation is that the ability of GM-CSF to delay neutrophil apoptosis may be inhibited by the simultaneous presence of other factors and/or cytokines in cell cultures. In fact, we recently demonstrated that in the presence of TNF- $\alpha$, GM-CSF was unable to delay apoptosis of neutrophils; rather, it induced a significant increase in their apoptotic rates (Salamone et al, 2001). This finding was confirmed by Daigle et al (2002), who showed that stimulation of death domaincontaining receptors of the TNF/nerve growth factor family disrupted antiapoptotic pathways initiated by survival factors such as GM-CSF in neutrophils. Additional studies are required to define the differences between the mechanisms through which platelets enhance survival of both eosinophils and neutrophils.

There is compelling evidence that links platelets and eosinophils in the development of allergic processes. However, the pathways through which platelets influence eosinophil behavior, as well as the impact of these pathways on the course of allergic processes, are not well defined. A better knowledge of these pathways will help toward the development of new strategies for the treatment of allergic diseases.

\section{Materials and Methods}

\section{Reagents}

Acridine orange, ethidium bromide, propidium iodide, collagen, thrombin, pronase, rhGM-CSF, and rhlL-3 were purchased from Sigma. The $\mathrm{mAb}$ anti-human 
CD16 (clone 3G8, mouse IgG1) used in eosinophil purification was obtained from Immunotech (Marseille, France). Neutralizing antibodies directed to human GM-CSF and IL-3 were from Pharmingen (San Diego, California). FITC mAb to P-selectin was also from Immunotech.

\section{Blood Samples}

Blood samples were obtained from healthy donors who had not taken medication for at least 10 days before the day of sampling. Blood was obtained by venipuncture of the forearm vein, and it was drawn directly into plastic tubes containing 3.8\% sodium citrate $(1 / 9 \mathrm{vol} / \mathrm{vol})$.

\section{Purification of Eosinophils}

Peripheral blood polymorphonuclear cells were obtained by dextran sedimentation and Ficoll-Hypaque gradient centrifugation, as previously described (Boyum, 1968). Contaminating erythrocytes were removed by hypotonic lysis. After washing, the fraction containing polymorphonuclear cells were resuspended in RPMI 1640 and were incubated with saturating concentrations of anti-CD16 mAb, for $45 \mathrm{~min}-$ utes at $4^{\circ} \mathrm{C}$. Then, cells were washed twice and eosinophils were isolated by negative selection using magnetic beads coated with anti-mouse IgG antibodies (Dynabeads M450; Dynal, Oslo, Norway), according to the manufacturer's instructions. Eosinophils were collected at a purity higher than 94\% and at a viability of 97 to $100 \%$, as assessed by trypan blue staining, and were resuspended in RPMI 1640 (Life Technologies, Grand Island, New York) supplemented with $1 \%$ of HSA, $100 \mu \mathrm{g} / \mathrm{ml}$ streptomycin, and 100 $\mu \mathrm{g} / \mathrm{ml}$ penicillin (Gibco Laboratories, Grand Island, New York).

\section{Preparation of Washed Platelets}

Platelet-rich plasma (PRP) was prepared by centrifugation of the citrated blood samples at $180 \times g$ for 10 minutes. Then, PRP was centrifuged in the presence of EDTA (5 mmol/L) for 15 minutes at $1500 \times g$, and platelets were washed twice $(1500 \times g$ for 15 minutes) in $0.015 \mathrm{~mol} / \mathrm{L}$ Tris, $0.145 \mathrm{~mol} / \mathrm{L} \mathrm{NaCl}, 0.002 \mathrm{~mol} / \mathrm{L}$ EDTA, $0.1 \%$ glucose, and $0.05 \%$ BSA (pH 6.5; TrisEDTA) and finally resuspended at the desired concentration in RPMI 1640 supplemented with $1 \%$ of HSA, $100 \mu \mathrm{g} / \mathrm{ml}$ streptomycin, and $100 \mu \mathrm{g} / \mathrm{ml}$ penicillin. The purity of platelet preparations was higher than $99.9 \%$ as judged by microscopic observation.

\section{Preparation of GFP}

PRP, in the presence of PGE1 $(0.1 \mu \mathrm{mol} / \mathrm{L})$, was gel-filtered on Sepharose 2B (Pharmacia, Uppsala, Sweden) as previously described (McCrae et al, 1990), using an elution buffer containing $0.137 \mathrm{~mol} / \mathrm{L} \mathrm{NaCL}$, $0.027 \mathrm{~mol} / \mathrm{L} \mathrm{KCl}, 0.001 \mathrm{~mol} / \mathrm{L} \mathrm{MgCl}_{2}, 0.0033 \mathrm{~mol} / \mathrm{L}$ $\mathrm{NaH}_{2} \mathrm{PO}_{4}, 0.1 \%$ glucose, $0.3 \% \mathrm{HSA}$, and $0.020 \mathrm{~mol} / \mathrm{L}$
HEPES ( $\mathrm{pH}$ 7.4). The purity of GFP was higher than $99.9 \%$ as judged by microscopic observation.

\section{Culture of Eosinophils with Platelets}

Unless otherwise stated, human eosinophils $(1 \times$ $10^{6} / \mathrm{ml}$ ) were cultured in the absence or presence of platelets (eosinophil:platelet ratios $=1: 50,1: 25$, or $1: 10)$ for different times at $37^{\circ} \mathrm{C}$ in $5 \% \quad \mathrm{CO}_{2}-95 \%$ humidified air. Then, the percentages of apoptotic eosinophils were determined by fluorescence microscopy and/or by flow cytometry. In all cases, platelets and eosinophils were isolated from the same donor for each assay. In experiments aimed to investigate the participation of soluble factors in the delayed apoptosis of eosinophils mediated by platelets, co-cultures of eosinophils and platelets were performed using TransWell culture inserts. Platelets or culture medium (controls) were placed in the lower compartment of 48-well flat-bottom plates at a total volume of $600 \mu \mathrm{l}$, and eosinophils were added into $0.4 \mu \mathrm{m}$ poro size inserts (upper compartment; Costar, Cambridge, MA) at an eosinophil:platelet ratio of 1:50. With the use of this method, eosinophils in the upper compartment were physically separated from platelets in the lower compartment, whereas the passage of macromolecules across the semipermeable membrane was allowed.

\section{Quantification of Eosinophil Apoptosis and Viability by Fluorescence Microscopy}

Quantification was performed as previously described (Coligan et al, 1994), using the fluorescent DNAbinding dyes acridine orange $(100 \mu \mathrm{g} / \mathrm{ml})$ to determine the percentage of cells that had undergone apoptosis and ethidium bromide $(100 \mu \mathrm{g} / \mathrm{ml})$ to differentiate between viable and nonviable cells. With this method, nonapoptotic cell nuclei show variations in fluorescent intensity that reflect the distribution of euchromatin and heterochromatin. By contrast, apoptotic nuclei exhibit highly condensed chromatin that is uniformly stained. For determining the percentage of eosinophils showing nuclear morphologic features of apoptosis, at least 200 cells were scored in each experiment. The percentage of necrotic cells was determined by counting ethidium bromide-positive cells.

\section{Quantification of Eosinophil Apoptosis by Annexin-V Binding Assay}

Annexin- $V$ binding to eosinophils was performed using an apoptosis detection kit (Immunotech). Cells were labeled with annexin-V FITC and propidium iodide for 20 minutes at $4^{\circ} \mathrm{C}$ and analyzed by twocolor flow cytometry (FACScan flow cytometer; Becton-Dickinson Immunocytometry System, San Jose, California) using CellQuest analysis software (Becton Dickinson), as previously described (Homburg et al, 1995). 


\section{Quantification of Eosinophil Apoptosis by Propidium lodide Staining and Flow Cytometry}

The proportion of eosinophils that display a hypodiploid DNA peak ie apoptotic cells, was determined using a modification of Nicoletti's protocol (Nicoletti et al, 1991). Briefly, cell pellets containing $2 \times 10^{5}$ eosinophils were suspended in $400 \mu \mathrm{l}$ of hypotonic fluorochrome solution (propidium iodide, $50 \mu \mathrm{g} / \mathrm{ml}$ in $0.1 \%$ sodium citrate plus $0.1 \%$ Triton $\mathrm{X}-100$ ) and incubated for 2 hours at $4^{\circ} \mathrm{C}$. The red fluorescence of propidium iodide in individual nuclei was measured using a FACScan flow cytometer (Becton-Dickinson Immunocytometry System, San Jose, California). The forward scatter and side scatter of particles were simultaneously measured. Cell debris was excluded from analysis by raising the forward scatter threshold.

\section{Measurement of Fluctuations in Intracellular $\mathrm{Ca}^{2+}$ Concentrations}

Changes in $\left[\mathrm{Ca}^{2+}\right]_{i}$ were monitored using fluo-3/AM, as previously described (Kao et al, 1989). Briefly, eosinophils suspended at a concentration of $1 \times 10^{6}$ cells/ml in RPMI 1640 were incubated with $4 \mu \mathrm{M}$ fluo-3/AM for 30 minutes at $30^{\circ} \mathrm{C}$. Then, loaded cells were washed twice and resuspended at $2 \times 10^{6}$ cells/ml in RPMI 1640 supplemented with 1\% HSA. Aliquots of $50 \mu \mathrm{l}$ of this cell suspension were then added to $250 \mu$ l of RPMI 1640 containing $1 \%$ HSA and warmed at $37^{\circ} \mathrm{C}$. The samples were immediately loaded onto the flow cytometer, and the basal fluorescence (FL1) was recorded during 15 seconds. Then, supernatants from platelets $\left(5 \times 10^{8} / \mathrm{ml}\right)$ cultured for 18 hours at $37^{\circ} \mathrm{C}$ in RPMI medium supplemented with $1 \% \mathrm{HSA}$ were added (50 $\mu \mathrm{l})$, and the fluorescence was recorded during an additional 100 seconds. Acquisition of samples was performed at $37^{\circ} \mathrm{C}$, and fluctuations in $\left[\mathrm{Ca}^{2+}\right]_{i}$ were recognized as alterations in fluo-3 fluorescence intensity over time. Data were analyzed by using CellQuest software (Becton Dickinson, Mountain View, California). Cells that raised their $\left[\mathrm{Ca}^{2+}\right]_{\mathrm{i}}$ in response to stimulation, to higher levels than that shown by $97 \%$ of resting cells, were considered to be activated.

\section{Measurements of GM-CSF Production by Platelets}

Washed platelets $\left(5 \times 10^{8}\right.$ cells $/ \mathrm{ml}$ in RPMI 1640 medium supplemented with $1 \% \mathrm{HSA}$ ) were incubated for 18 hours at $37^{\circ} \mathrm{C}$. Then, supernatants were harvested, aliquotted, and quickly stored at $-70^{\circ} \mathrm{C}$ until used. The concentration of GM-CSF was assessed using a commercial enzyme immunoassay kit $(R \& D$ Systems, Minneapolis, Minnesota). The sensitivity of the cytokine test was $5 \mathrm{pg} / \mathrm{ml}$.

\section{Flow Cytometric Analysis of Intracellular GM-CSF in Fixed/Permeabilized Platelets}

Washed platelets $\left(10^{7}\right)$ were fixed and permeabilized using a commercial kit (Cytofix/Cytoperm; Pharmingen) and subsequently stained with $0.25 \mu \mathrm{g}$ of PE-rat anti-human GM-CSF mAb, clone BVD2-21C11 (Pharmingen). For demonstrating specificity of staining, the binding of the PE-BVD2-21C11 antibody was blocked by preincubation of the fixed/permeabilized platelets with $2.5 \mu \mathrm{g}$ of unlabeled BVD2-21C11 antibody (Pharmingen) before staining.

\section{Statistical Analysis}

Student's paired $t$ test was used to determine the significance of differences between means, and $p<$ 0.05 was taken as indicating statistical significance.

\section{Acknowledgements}

We thank Selma Tolosa and Nelly Villagra for technical assistance and Maria Rita Furnkorn for secretarial assistance.

\section{References}

Alam R, Forsythe P, Stafford S, and Fukuda Y (1994). Transforming growth factor beta abrogates the effects of hematopoietins on eosinophils and induces their apoptosis. $J$ Exp Med 179:1041-1045.

Andonegui G, Trevani A, López D, Raiden S, Giordano M, and Geffner J (1997). Inhibition of human neutrophil apoptosis by platelets. J Immunol 158:3372-3377.

Blaylock MG, Sexton DW, and Walsh GM (1999). Ligation of CD45 and the isoforms CD45RA and CD45RB accelerates the rate of constitutive apoptosis in human eosinophils. J Allergy Clin Immunol 104:1244-1250.

Boyum A (1968). Separation of leukocytes from blood and bone marrow. J Lab Invest 22(Suppl 97):77-85.

Burgers JA, Schweizer RC, Koenderman L, Bruijnzeel PLB, and Akkerman JWN (1993). Human platelets secrete chemotactic activity for eosinophils. Blood 81:49-55.

Chihara J and Nakajima S (1989). Platelet factor 4 has chemotactic activity for eosinophils and augments Fc gamma and $\mathrm{Fc} \gamma$ receptor expression on eosinophils. In: Morley $\mathrm{J}$ and Colditz I, editors. Perspectives in asthma. Eosinophils in asthma. London: Academic Press, 151-159.

Coligan JE (1994). Morphological and biochemical assays of apoptosis. In: Coligan JE, Kruibeek AM, Margulies AH, Shevach EM, and Strober $W$, editors. Current protocols in immunology. New York: John Wiley \& Sons, 3.17-3.22.

Costa JJ, Weller PF, and Galli SJ (1997). The cells of the allergic response. JAMA 278:1815-1822.

Coyle AJ, Page CP, Atkinson L, Flanagan R, and Metzger WJ (1990). The requirement for platelets in allergen-induced late asthmatic airway obstruction. Eosinophil infiltration and heightened airway responsiveness in allergic rabbits. Am Rev Respir Dis 142:587-593.

Daigle I, Yousefi S, Colonna M, Green DR, and Simon HU (2002). Death receptors bind SHP-1 and block cytokineinduced anti-apoptotic signaling in neutrophils. Nat Med 8:61-67.

Deuel TF, Señor RM, Huang JS, and Griffin GL (1982). Chemotaxis of monocytes and neutrophils to platelet derived growth factor. J Clin Invest 69:1046-1049. 
Dombrowicz D and Capron M (2001). Eosinophils, allergy and parasites. Curr Opin Immunol 13:16-20.

Esnault S and Malter JS (2001). Granulocyte macrophagecolony-stimulating factor mRNA is stabilized in airway eosinophils and peripheral blood eosinophils activated by TNFalpha plus fibronectin. J Immunol 166:4658-4663.

Gleich GJ (1990). The eosinophil and bronchial asthma: Current understanding. J Allergy Clin Immunol 85:422-436.

Gleich GJ (2000). Mechanisms of eosinophil-associated inflammation. J Allergy Clin Immunol 105:651-663.

Grainger DJ, Mosedale DE, Metcalfe JC, Weissberg PL, and Kemp PR (1995). Active and acid-activatable TGF-beta in human sera, platelets and plasma. Clin Chim Acta 235:1131.

Haslett C (1999). Granulocyte apoptosis and its role in the resolution and control of lung inflammation. Am J Respir Crit Care Med 160(5 Pt 2):S5-S11.

Hawrylowicz CM, Santoro SA, Platt FM, and Unanue ER (1989). Activated platelets express IL-1 activity. J Immunol 43:4015-4018.

Homburg CHE, De Haas M, von dem Borne AEG, Verhoeven AJ, Reutelingsperger CPM, and Roos D (1995). Human neutrophils lose their surface $\mathrm{Fc} \gamma \mathrm{R}$ and acquire annexin $\mathrm{V}$ binding sites during apoptosis in vitro. Blood 85:532-540.

Jian S, Levine JD, Fu Y, Deng B, London R, Groopman JE, and Avraham $\mathrm{H}$ (1994). Cytokine production by bone marrow megakaryocytes. Blood 84:4151-4156.

Kameyoshi Y, Dorschner A, Mallet Al, Christophers E, and Schroder JM (1992). Cytokine RANTES released by thrombin-stimulated platelets is a potent attractant for human eosinophils. J Exp Med 176:587-592.

Kao JPY, Harootunian AT, and Tsien RY (1989). Photochemically generated cytosolic calcium pulses and their detection by fluo-3. J Biol Chem 264:8179-8184.

Knauer KA, Lichtenstein LM, Adkinson NF, and Fish JE (1981). Platelet activation during antigen-induced airway reactions in asthmatic subjects. N Engl J Med 304:1404-1407.

Lellouch-Tubiana A, Lefort J, Simon MT, Pfister A, and Vargaftig BB (1988). Eosinophil recruitment into guinea pig lungs after PAF-acether and allergen administration. Modulation by prostacyclin, platelet depletion, and selective antagonists. Am Rev Respir Dis 137:948-954.

Levi-Schaffer FL, Temkin V, Malamud V, Feld S, and Zilberman $Y$ (1998). Mast cells enhance eosinophil survival in vitro: Role of TNF- $\alpha$ and granulocyte-macrophage colonystimulating factor. J Immunol 160:5554-5562.

Lopez AF, Williamson DJ, Gamble JR, Begley CG, Harlan JM, Klebanoff SJ, Waltersdorph A, Wong G, Clark SC, and Vadas MA (1986). Recombinant human granulocyte-macrophage colony-stimulating factor stimulates in vitro human mature neutrophil and eosinophil function, surface receptor expression, and survival. J Clin Invest 78:1220-1228.

Luttman W, Knoechel B, Foerster M, Matthys H, Virchow JC, and Kroegel C (1996). Activation of human eosinophils by IL-13. J Immunol 157:1678-1683.

McCrae KR, Shattil SJ, and Cines DB (1990). Platelet activation induced increased Fc receptor expression. J Immunol 144:3920-3297.

McEver RP (1994). Selectins. Curr Opin Immunol 6:75-84.
Mogbel R, Hamid Q, Ying S, Barkans J, Hartnell A, Tsicopoulos A, Wardlaw AJ, and Kay AB (1991). Expression of mRNA and immunoreactivity for the granulocyte/macrophage colony-stimulating factor in activated human eosinophils. J Exp Med 174:749-752.

Morley J, Sanjar S, and Page CP (1985). The platelet in asthma. Lancet 2:726-727.

Nicoletti I, Migliorati G, Pagliacci MC, Grignani F, and Ricciardi C (1991). A rapid and simple method for measuring thymocyte apoptosis by propidium iodide staining and flow cytometry. J Immunol Methods 139:271-279.

Nimer SD and Uchida H (1995). Regulation of granulocytemacrophage colony-stimulating factor and interleukin 3 expression. Stem Cells 13:324-335.

Nimer S, Zhang J, Avraham H, and Miyazaki Y (1996). Transcriptional regulation of interleukin-3 expression in megakaryocytes. Blood 88:66-74.

Nutku E, Zhuang Q, Soussi-Gounni A, Aris F, Mazer BD, and Hamid Q (2001). Functional expression of IL-12 receptor by human eosinophils: IL-12 promotes eosinophil apoptosis. J Immunol 167:1039-1046.

Okada S, Hagan JB, Kato M, Bankers-Fulbright JL, Hunt LW, Gleich GJ, and Kita H (1998). Lidocaine and its analogues inhibit IL-5-mediated survival and activation of human eosinophils. J Immunol 160:4010-4017.

Page CP (1988). The involvement of platelets in nonthrombotic processes. Trends Pharmacol Sci 9:66-71.

Page CP and Coyle AJ (1989). The interaction between PAF, platelets and eosinophils in bronchial asthma. Eur Respir $\mathrm{J}$ Suppl 6:483-487.

Perssen CGA and Erjefalt JS (1997). Ultimate activation of eosinophils in vivo: Lysis and release of clusters of free eosinophil granules. Thorax 52:569-574.

Platt N, da Silva RP, and Gordon S (1998). Recognizing death: The phagocytosis of apoptotic cells. Trends Cell Biol 3:356-372.

Rothenberg ME, Owen WF, and Silberstein DS (1988). Human eosinophils have prolonged survival, enhanced functional properties, and become hypodense when exposed to human interleukin-3. J Clin Invest 81:1986-1992.

Salamone G, Giordano M, Trevani A, Gamberale R, Vermeulen M, and Geffner J (2001). Promotion of neutrophil apoptosis by TNF- $\alpha$. J Immunol 166:3476-3482.

Shao-Bo S, Mukaida N, and Matsushima K (1996). Rapid secretion of intracellularly pre-stored interleukin-8 from rabbit platelets upon activation. J Leuk Biol 59:420-426.

Simon HU and Blazer K (1995). Inhibition of programmed eosinophil death: A key pathogenic event for eosinophilia? Immunol Today 16:53-55.

Stern M, Savill J, and Haslett C (1996). Human monocytederived macrophage phagocytosis of senescent eosinophils undergoing apoptosis: Mediation by $\alpha$ v $\beta 3 / C D 36 /$ thrombospondin recognition mechanism and lack of phlogistic response. Am J Pathol 149:911-921.

Tai PC, Sun L, and Spry CJ (1991). Effects of IL-5, granulocyte/macrophage colony-stimulating factor (GM-CSF) and IL-3 on the survival of human blood eosinophils in vitro. Clin Exp Immunol 85:312-316. 
Trevani A, Andonegui G, Giordano M, Nosari M, Fontán P, and Geffner JR (1996). Neutrophil apoptosis induced by proteolytic enzymes. Lab Invest 74:711-721.

Wallen N, Kita H, Weiler D, and Gleich J (1991). Glucocorticoids inhibit cytokine mediated eosinophil survival. J Immunol 147:3490-3495.

Walsh GM (2000). Eosinophil apoptosis: Mechanisms and clinical relevance in asthmatic and allergic inflammation. $\mathrm{Br} \mathrm{J}$ Haematol 111:61-67.

Walsh GM, Sexton DW, Blaylock MG, and Convery CM (1999). Resting and cytokine-stimulated human small airway epithelial cells recognize and ingest apoptotic eosinophils. Blood 94:2827-2835.

Walsh GM, Williamson ML, Symon FA, Willars GB, and Wardlaw AJ (1996). Ligation of CD69 induces apoptosis and cell death in human eosinophils cultured with granulocytemacrophage colony-stimulating factor. Blood 87:2815-2821.

Wardlaw AJ, Moqbel R, Cromwell O, and Kay AB (1986). Platelet activating factor: A potent chemotactic and chemokinetic factor for human eosinophils. J Clin Invest 78:17011706.
Weidi B, Raap U, Lewrick H, and Kapp A (1998). IL-4-induced apoptosis in peripheral blood eosinophils. J Allergy Clin Immunol 102:1013-1020.

Wickenhauser C, Lorenzen J, Thiele J, Hillienhof A, Jungheim K, Schmitz B, Hansmann ML, and Fischer R (1995). Secretion of cytokines (interleukins- 1 alpha, -3 , and -6 and granulocyte-macrophage colony-stimulating factor) by normal human bone marrow megakaryocytes. Blood 85:685691.

Yamaguchi Y, Suda T, Ohta S, Tominaga K, Miura Y, and Kasahara T (1991). Analysis of the survival of mature human eosinophils: Interleukin-5 prevents apoptosis in mature human eosinophils. Blood 78:2542-2547.

Yasuba H, Chihara J, Kino T, Satake N, and Oshima S (1991). Increased releasability of platelet products and reduced heparin-induced platelet factor 4 release from endothelial cells in bronchial asthma. J Lipid Mediat 4:5-21. 